\title{
The Frequency and Importance of Accurate Heritage Name Pronunciation for Post-Secondary International Students in Canada
}

\author{
Ying Shan Doris Zhang \\ Kimberly A. Noels \\ University of Alberta, Canada
}

\begin{abstract}
International students' names are often mispronounced, and this experience can have psychological and relational implications for some students' cross-cultural adjustment. Little research, however, has examined why students are or are not bothered by mispronunciations. This study examined the impact of heritage name mispronunciation on 173 language-minority international students in Canada. The results indicated that although heritage name mispronunciations occurred frequently, only about half of the sample perceived correct pronunciation as important. Those who felt accurate pronunciation was important stressed that their name had a strong connection to their heritage and that mispronunciations were disrespectful of that significance. Those who felt accurate pronunciation was not important cited little personal connection to the name and accepted mispronunciations for reasons of efficiency. The findings suggest that accurate heritage name pronunciation can facilitate the adjustment of international students by fostering positive affect, communicative comfort, and relational closeness during cross-cultural interactions in the host countries.
\end{abstract}

Keywords: adaptation, intercultural relations, international students, name mispronunciation 
A name pronounced is the recognition of the individual to whom it belongs. He who can pronounce my name aright... is entitled to my love and service.

\section{—Henry David Thoreau}

Name mispronunciations are common experiences that we each encounter at some point of our lives, especially for individuals with names in a foreign language. As the struggle to accurately articulate another's name usually stems from language differences, mispronunciation may be especially prevalent during cross-cultural interactions. This common occurrence has several negative effects. Studies have shown that ethnolinguistic minority students react aversively to others' mispronunciation of their heritage/ethnic names, resulting in feelings of uneasiness, shame, and embarrassment (Yoon, 2018). Heritage name mispronunciations can also induce communicative inconveniences that make cross-cultural interactions hasslesome. In an effort to avoid encountering mispronunciations, anglicizing one's given name is a common decision among language-minority students in English-speaking countries (Pennesi, 2014).

Although research attention has grown over the past decade documenting the "mainstreaming" of ethnic names in the receiving society (Edwards \& Caballero, 2008; Zhao \& Biernat, 2018), relatively little is known about language-minority students' personal experiences with heritage name mispronunciations. Since a heritage name may hold personal significance to the name bearer due to ties with one's family and ethnic culture (Bramwell, 2016), mispronunciations may subject ethnolinguistic minority students to microaggressions, in the forms of subtle racial slights and disrespect, regardless of intentionality (Smith et al., 2007).

As a major group of the language-minority student population, international students are no stranger to the experience of having their heritage names mispronounced in their host country. However, very few studies to date have investigated the impact of heritage name mispronunciation on international students (Kim, 2011; Ruzicka, 2018), despite its potential association with hassles and microaggressions, both of which can present damaging consequences to the students' adjustment and well-being (Leong \& Ward, 2000). Given the potential harm of mispronunciations, the present study aims to address the research gap by inquiring into the experiences of heritage name mispronunciations among language-minority international students in Canada (e.g., to identify the frequency of heritage name mispronunciations and understand the importance behind pronunciation accuracy). This study also extends to examine how experiences with mispronunciations may differ by demographic and immigration-related factors (e.g., gender, nationality, year of study, and permanent residency plans in Canada), which could impact the students' personal ties with their heritage names. To this end, we first review the existing scholarship on the significance of personal names, and provide a description of the potential harms of mispronunciations, before proceeding to the current study. 


\section{LITERATURE REVIEW}

\section{"What's in a Name?"}

Names can be given to a broad range of nouns/entities (e.g., personal names, place names, animal names, etc.); the current study revolves around personal names, which pertain to names bestowed upon persons usually by their parents. Personal names may be central to our unique sense of self, and/or indicative of our group memberships. Personal names can also "tell stories" about the people, events, and the society that surround the name-carriers (Bramwell, 2016). For some people, personal names can be ingrained into the name-carriers, such that the person and the name become "one" and may be perceived to share the same underlying characteristics (Nyström, 2016).

Within the family context, personal names may serve as a medium through which parents impart their visions, blessings, or any meaningful message they wish to communicate to their offspring (Zittoun, 2004). Names can also communicate identification with a particular family. For instance, Alford (1988) argues that a shared surname (or family name) signifies a cross-generational linkage with other family members, as well as with the history of the entire family. Likewise, first names (or given names) can also constitute an important part of a person's family identity. In some cases, given names are passed on across generations, in forms of blessings to the newborn and in commemoration of the forebears, thereby ensuring the virtue of the family lives on (Leibring, 2016).

Personal names can also indicate ethnic group memberships and be entwined with ethnocultural identities (Quaglia et al., 2016). Different ethnocultural groups have different naming systems, practices, and rituals. Compliance with local naming practices and the use of local names communicate "in-group" membership and provide a sense of group solidarity (Brandes, 1975). Nonetheless, some ethnic minority groups might purposely adopt personal names that differ from the societal majority to assert their distinctive ethnic identities (Chelliah, 2005).

Due to all of the personal, familial, and ethnocultural information embedded in them, names can be packed with meaning and emotions. Upon hearing a name, one's thoughts, memories, and feelings associated with that name could be primed (Nyström, 2016). The associative meanings of personal names are extended to the name-bearers, shaping social impressions (Sidhu \& Pexman, 2019). Therefore, a thorough understanding of how our names may be attached to who we are as individuals, and to our projected social image, is critical to appreciating the need for accurate pronunciation. 


\section{Mispronunciation of Names: Why It Matters}

Philosopher Francis Cornford once said, "[T] he name of a thing... is its soul" (1957, p. 141). Given that people are bonded to their names, a distortion of that name could be perceived as a violation of one's self-image (Payne et al., 2018). Mispronunciation occurs frequently during intercultural encounters largely because of unfamiliarity with the linguistic system. Although the act of mispronouncing another's name may be entirely unintentional and benign, it nevertheless can have negative psychological and relational implications. For instance, international students reported feeling embarrassment or shame when their heritage names were mispronounced (Kim, 2011). This feeling may be especially salient among international students whose heritage names are in tonal languages (e.g., Mandarin and Cantonese), the meaning of which could be greatly altered if mispronounced. The altered tones may result in a word that is disrespectful and mocking to the students and negatively impact their class attendance and participation (Chen, 2016).

Repeated encounters with name mispronunciations may also feel like daily hassles to international students, as they navigate their new lives in the host country. These daily inconveniences or hassles, resulting from ethnolinguistic differences, may subject international students to varying degrees of distress and emotional harm (Le, 2018; Leong \& Ward, 2000). Furthermore, the mispronunciation may be construed as more than a tiresome hassle. Inattentiveness in heritage name pronunciation might cause ethnic minority students to feel scorned and belittled because of their heritage differences, especially if the mispronunciations come from members of the ethnocultural majority (Pennesi, 2016). Consequently, international students could also perceive hosts' mispronunciations as racial slights that are construed as subtle forms of discrimination (i.e., microaggressions; Smith et al., 2007).

Despite the harmful impacts of mispronunciations, constructive efforts to correct the pronunciation of minority names appear to be lacking. It is not unusual for members of the host society, including teachers and employers, to request language minorities to change their names as a "resolution" (Kim, 2011). In their interviews with ethnic minority students in K-12 schools, Kohli and Solórzano (2012) found that when teachers encountered difficulties pronouncing their students' names, they directly asked the students to change their names, or in some cases, assigned the students with new names that the teachers found easier to articulate. This act of heritage name removal in order to increase the teachers' communicative convenience can be construed as a racial slight by the student.

In other cases, language-minority students may voluntarily adopt a name from the mainstream language to avoid the consequences of mispronunciation (Pennesi, 2014). Although voluntary, this act of renaming results in a one-sided adaptation by the affected students to overcome mispronunciation issues, possibly at the cost of compromising personal ties with their long-held heritage names (Yoon, 2018). Meanwhile, the lack of effort from host teachers in using minority students' names properly suggests these teachers (1) have insufficient awareness on the importance of heritage names to the name-bearers, (2) underestimate the 
deleterious effects of mispronunciation, and/or (3) lack the skill to pronounce the name properly. It is not inconceivable that, in some hopefully rare cases, this lack of insight or skill might be accompanied by prejudiced attitudes.

\section{THE CONTEXT AND OBJECTIVES OF THE CURRENT STUDY}

The current study is situated in Canada, which has grown increasingly popular as a country of destination for foreign students seeking an international education (Canadian Bureau for International Education [CBIE], 2019). International students are important contributors to Canadian society because of the enrichment they bring to the Canadian cultural and educational context by sharing their diverse cultural perspectives (Canadian Alliance of Student Associations, 2018). They also support the Canadian economy and labor market via enhancing the nation's human capital (Blatchford, 2019).

Because of these contributions, almost all post-secondary institutions put considerable effort into attracting and retaining international students by offering various academic, social, and career support services (Martirosyan et al., 2019). Yet, research on the potential impact of heritage name mispronunciations to international students is lacking. The few available studies have associated hosts' mispronunciations with adaptation stressors, such as racism, negative affect, and a lack of collaborative effort from host members in the adjustment process of international students (Chen, 2016; Kim, 2011; Ruzicka, 2018). However, little research has looked into (1) the specific reasons for why international students would feel that proper pronunciation of their names is important or not, and (2) whether the perceived frequency and criticality of heritage name mispronunciations would differ by demographic variables and postgraduation residency plans, as these factors may influence the students' personal ties with their heritage names. This study seeks to fill this gap.

Utilizing qualitatively driven mixed-method research (Morse \& Cheek, 2014), the present study aims to incorporate the voices of language-minority international students in Canada into an inquiry about the experience of heritage name mispronunciations. Specifically, this study attempts to (1) determine the frequency of mispronunciations on international students' heritage names, (2) assess the perceived importance of accurate pronunciations among international students, and (3) explore and identify the students' reasons for why they perceived pronunciation accuracy to be important or not. Moreover, we will examine whether the perceptions of frequency and importance differ by the respondents' gender, nationality, year of study, and future plan concerning permanent residency in Canada.

\section{METHOD}

\section{Participants}

To gain convenient access to a large international student sample, we recruited international students $(n=173)$ who spoke a native language other than 
English from the psychology research participation pool at a western Canadian university. Seventy-three participants were males and 100 were females. The average age of participants was $19.76(S D=2.07)$ with a range from 17 to 35 years of age. Their countries of citizenship included China (61.8\%), India (5.8\%), Japan (5.2\%), Vietnam (5.2\%), South Korea (4.6\%), Bangladesh (2.9\%), Pakistan $(2.3 \%)$, Kenya $(1.7 \%)$, Iran $(1.2 \%)$, Ukraine $(1.2 \%)$, Cuba $(0.6 \%)$, Ethiopia $(0.6 \%)$, Ghana $(0.6 \%)$, Grenada $(0.6 \%)$, Iraq $(0.6 \%)$, Lebanon $(0.6 \%)$, Mauritius $(0.6 \%)$, Mexico $(0.6 \%)$, Nigeria $(0.6 \%)$, Sierra Leone $(0.6 \%)$, Sri Lanka $(0.6 \%)$, Sudan $(0.6 \%)$, Taiwan $(0.6 \%)$, and Tanzania $(0.6 \%)$. The distribution of the sample's nationalities generally paralleled the distributions at the university and national level (CBIE, 2019; University of Alberta, 2020).

Slightly more than half of the sample $(51.4 \%)$ were in the first year of their studies, $28.8 \%$ were in their second year, and $14.4 \%$ were in their third year or above.

\section{Materials and Procedure}

To explore the prevalence and significance of heritage name mispronunciations among language-minority international students, the participants responded to questions via an online survey that asked, "How often is your heritage name mispronounced by others in Canada" and "How important is it for you to have your heritage name accurately pronounced by others in Canada?" Responses were collected using 5-point Likert scales, ranging from 1 (Almost never/Not important at all) to 5 (Almost always/Very important). The participants also responded to an open-ended question that elicited their personal perspectives around pronunciation accuracy (e.g., "Please provide detailed reasons on why it is or is not important for you to have your heritage name correctly pronounced by others in Canada"). Demographic information was also collected, as well as whether the students intend to obtain permanent residency in Canada after graduation.

The data collection took place in a secure computer laboratory, monitored by research assistants. All participants submitted the questionnaire and received research participation credit for their course. The completion rate for the questions was approximately $94 \%$, as the participants had the right to pass on questions that they did not wish to answer.

\section{Analytic Strategy}

Two major sets of analyses were conducted. First, we examined whether the perceived frequency and criticality of heritage name mispronunciations would differ across several demographic and immigration-related variables (e.g., gender, nationality, year of study, and future residency plan in Canada) using t-tests and one-way ANOVAs on SPSS.

Second, a thematic analysis was conducted on the open-ended responses, which enlisted the reasons for why the participants would regard accurate heritage name pronunciation as important or not. The responses were divided and analyzed in three different groups that varied in the degree of perceived importance, which 
allowed us to more accurately capture the distinct reasons behind each level of importance perception. In response to the question, "How important is it for you to have your heritage name accurately pronounced by others in Canada," participants with importance ratings of "1" and "2" on the 5-point Likert scale were assigned into a group that placed relatively low importance on correct heritage name pronunciations. Participants who gave ratings of "3" (midpoint on the scale) were assigned to the "middle group" that perceived correct pronunciations as somewhat important. Finally, participants with ratings of " 4 " and " 5 " were assigned to a group that placed relatively high importance on the correct pronunciation of their heritage names.

After the groups were created, thematic analysis was performed in Nvivo on the responses within each group, following the guidelines proposed by Braun and Clarke (2006). Specifically, after all responses were thoroughly read, preliminary codes were generated by three independent coders to capture the essence of each response. Due to the potential linkage between heritage name mispronunciations, daily hassles, and microaggressions, we looked for information that indicated social/communicative inconveniences and racial disrespect when developing the specific codes, while remaining open to other perspectives that emerged from the responses. Similar codes were collated to form themes that highlighted key information shared among the responses. To achieve objectivity and meet the dependability criteria of rigorous qualitative research (Lincoln \& Guba, 1986), discrepancies in coding and the refinement of themes were discussed among all independent coders until consensus was reached.

\section{RESULTS}

\section{Perceived Frequency and Importance of Name Mispronunciation}

The frequency and importance of heritage name mispronunciations among international students are displayed in Table 1 . As shown, 24.8\% of respondents reported that their heritage names were almost never or rarely mispronounced; $24.9 \%$ indicated sometimes; and $50.3 \%$ reported their names were often or almost always mispronounced by others in Canada. The perceived importance of correct heritage name pronunciations was low for $51.4 \%$ students, somewhat important for $22 \%$, and relatively high in importance for $26.6 \%$ of the participants. The correlation between perceived frequency and importance was statistically significant but quite low $(r=-0.17, p=0.026)$, indicating a slight tendency for those who experienced more frequent mispronunciations of their name to consider mispronunciations to be less important. However, given the small effect size $\left(R^{2}=0.03\right.$; Cohen, 1988), the relation between perceived frequency and importance of name mispronunciation can be considered negligible. 
Table 1: Perceived Frequency and Importance of Heritage Name Mispronunciation

\begin{tabular}{lllll}
\hline & \multicolumn{2}{l}{ Frequency } & \multicolumn{2}{l}{ Importance } \\
\cline { 2 - 5 } Rating Score & $n$ & $\%$ & $n$ & $\%$ \\
\hline 1 & 17 & 9.8 & 40 & 23.1 \\
2 & 26 & 15 & 49 & 28.3 \\
3 & 43 & 24.9 & 38 & 22 \\
4 & 34 & 19.7 & 31 & 17.9 \\
5 & 53 & 30.6 & 15 & 8.7 \\
\hline Note: $n=$ Number of participants with the corresponding score.
\end{tabular}

A series of analyses were conducted to assess whether the rates of perceived frequency and importance differed across several demographic and immigrationrelated variables that might impact these perceptions. The results showed that the perceived frequency and importance did not significantly vary by the participants' gender, year of study, and future residency plans in Canada. However, a significant difference in the perceptions was found based on nationality. Since a majority of the sample originated from Asia and only a limited subsample from non-Asian regions, a comparison across regions within the non-Asian subsample was not feasible. Thus, two one-way ANOVAs were conducted to compare participants who arrived from East Asia, South Asia, and other regions in the world. No significant difference was found in the perceived frequency of mispronunciations across regions of origin, but there was a significant difference with regard to perceived importance, $F(2,170)=6.02, p=0.003, \eta^{2}=0.07$. Particularly, participants from other regions of the world felt that it was more important to say their heritage names accurately $(M=3.53, S D=1.35, n=19)$ than did people from East Asia $(M=2.50, S D=1.21, n=134)$ and South Asia $(M=2.45, S D=1.19, n=20)$. However, due to the large disparity in the numbers of participants in each region, the region variable was not included in subsequent analyses.

\section{Rationale for Opinions Regarding Importance}

\section{Low Importance}

The respondents who perceived correct heritage name pronunciation to be relatively low in importance $(n=88$; see Table 2$)$ provided nine distinct categories of reasons for their opinions, which are described below according to their rank in the frequency of occurrence. The most frequently mentioned reason acknowledged the pronunciation difficulties experienced by non-native speakers due to language differences and barriers (Acknowledging and Understanding Pronunciation Difficulty; e.g., "They don't speak Chinese at all, so I think that's totally fine if they can't pronounced my name correctly"). The examples are provided verbatim, including the participants' grammar and spelling errors. 


\section{Table 2: Themes in the Personal Reasons of International Students Perceiving Correct Heritage Name Pronunciations as Relatively Unimportant $(n=88)$}

\begin{tabular}{|c|c|c|}
\hline Ranking & $\begin{array}{l}\text { Number of } \\
\text { references }\end{array}$ & Themes \\
\hline & & Reasons Supporting Lack of Importance \\
\hline 1 & 53 & $\begin{array}{l}\text { Acknowledging and Understanding } \\
\text { Pronunciation Difficulty }\end{array}$ \\
\hline 2 & 10 & Already Have and Use an English Names \\
\hline 2 & 10 & Little Significance in Names \\
\hline 3 & 7 & Low Interference with Social Recognition \\
\hline 4 & 6 & Lack of Ill-Intentions \\
\hline 5 & 4 & Expectation of Mispronunciation \\
\hline 5 & 4 & Name is Peripheral to Personal Identity \\
\hline 6 & 2 & $\begin{array}{l}\text { Satisfaction with Partially Correct } \\
\text { Pronunciations }\end{array}$ \\
\hline 6 & 2 & Pronunciations can be Improved \\
\hline- & 2 & Unimportance Unexplained \\
\hline- & 9 & Other \\
\hline- & 9 & $\begin{array}{l}\text { Reason Supporting Importance } \\
\text { Desire and Appreciation for Pronunciation } \\
\text { Accuracy and Effort }\end{array}$ \\
\hline
\end{tabular}

Note: Number of references refers to the total number each corresponding theme has appeared in the responses. Themes are ranked from the most referenced to the least referenced.

The participants who already have and use an English name perceived mispronunciations of heritage names as relatively low in importance (Already have and Use an English Names; e.g., "My English name is also a part of who I am. I believe that pronunciation is not really that important"). As well, some students perceived names merely as social tools, which in themselves held little significance. Thus, the degree to which names were accurately pronounced was unimportant (Little Significance in Names; e.g., "Name is just a label and I don't think the pronunciation of it is that important").

Moreover, the students also seemed accommodating of mispronunciations, as long as the mispronunciation did not prevent the students from being identified in social settings (Low Interference with Social Recognition; e.g., “... if I know they are calling me, that's fine"), and were not associated with discrimination and/or disrespect (Lack of Ill-Intentions; e.g., "It is not that a big deal as long as we do not do this intentionally and disrespectfully"). Furthermore, some students expected to experience mispronunciations in Canada, thereby viewing the phenomenon as "normal” (Expectation of Mispronunciation; e.g., "... my name 
is hardly pronounced well by people who are not Korean, and hearing that for most of my life made me feel nonchalant about it..."). As well, proper pronunciation was seen as relatively unimportant among international students who did not view their heritage name as central to their self-concept, such that “... I don't feel like my name is my identity" (Name is Peripheral to Personal Identity).

A lesser number of students also reported that they did not perceive correct pronunciation to be important because they were satisfied as long as the pronounced name at least partially resembled their actual heritage name (Satisfaction with Partially Correct Pronunciations; e.g., "I'm okay as long as it sounds somewhat like my name..."), and believed that pronunciations could be improved through corrections (Pronunciations can be Improved; e.g., "I will just correct them if they pronounce it wrong").

Two responses did not provide specific reasons or explanations (Unimportance Unexplained; e.g., "I personally think it doesn't matter"). Nine responses were grouped into the Other category as their content did not overlap with the other identified reasons (e.g., "I want to be known for what I do and not for who I am..."). One participant did not provide a response.

Interestingly, among the participants who perceived correct pronunciations as relatively unimportant, one theme emerged from their responses that underscored accurate heritage name pronunciations (Desire and Appreciation for Pronunciation Accuracy and Effort; e.g., "... it is after all the name my parents give me so it would still be great if people can learn to say it right," "... i think making an effort to try and say my name correctly is also important, because $\mathrm{i}$ don't think any of my international friends say any canadian names incorrectly").

\section{High Importance}

Among participants who rated correct heritage pronunciations as relatively important $(n=36$; see Table 3$)$, the most frequently stated reason was Personal Connections. Specifically, heritage names were meaningful to the respondents at the individual, family, and ethnocultural levels. Individually, heritage names were related to the students' self-identity, personality, and served to emphasize personal distinctiveness (e.g., "Cause when that's my real name and... my identity"). At the family level, heritage names may be given by or passed down from senior family members, which held great symbolic meanings (e.g., "I find it important because my heritage name... has great meaning and wishes. I think it is a gift from my grandfather who gave the name to me when I was born"). At the cultural level, heritage names could be representative of one's home country, thereby generating a feeling of "homeliness" (e.g., "It is an... representation of a Chinese," “... it does make me feel 'at home' when others pronounce my name with a Korean accent"). 


\section{Table 3: Themes in the Personal Reasons of International Students Perceiving Correct Heritage Name Pronunciations as Relatively Important $(n=43)$}

\begin{tabular}{|c|c|c|}
\hline Ranking & $\begin{array}{l}\text { Number of } \\
\text { references }\end{array}$ & Themes \\
\hline & & Reasons Supporting Importance \\
\hline \multirow[t]{4}{*}{1} & 32 & Personal Connections \\
\hline & 22 & - Individual \\
\hline & 6 & - Familial \\
\hline & 4 & - Ethno-cultural \\
\hline 2 & 9 & Respect \\
\hline 3 & 6 & Facilitating Social Recognition \\
\hline 4 & 5 & Facilitating Host Relatedness and Belonging \\
\hline 5 & 4 & Affective Ties \\
\hline 6 & 3 & Reciprocal Efforts \\
\hline 7 & 2 & Appreciation for Pronunciation Efforts \\
\hline- & 2 & Deserving of Correct Pronunciation \\
\hline- & 1 & Other-Linguistic Prescriptivism \\
\hline & & Reasons Supporting Lack of Importance \\
\hline- & 6 & Understanding Pronunciation Difficulties \\
\hline
\end{tabular}

Note: Number of references refers to the total number each corresponding theme has appeared in the responses. Themes are ranked from the most referenced to the least referenced.

The second most commonly stated reason underlining the perceived importance was the conveyance of respect toward one's country, ethnic group, family, and self (Respect; e.g., "My heritage name is a symbol of myself, so I think pronounce it correctly will show the respect to me, and I do not want to be discriminated," "... my name is named by my parents, pronounced correctly also can show respects to them," "Pronouncing it correctly shows respect to Chinese people and culture"). Moreover, correct heritage name pronunciation was deemed important because it facilitated social recognition (Facilitating Social Recognition; e.g., "Sometimes I do not realize someone is calling me if my heritage name pronounced incorrectly"), and induced a sense of connectedness to the host community among the students (Facilitating Host Relatedness and Belonging; e.g., "It is important for me to have my heritage pronounced correctly because it make me feel belong"). As well, another reason underlying the importance in correct pronunciation was related to the emotional ties the respondents had with their heritage names (Affective Ties; e.g., "Because I love my name..."). 
Furthermore, a few respondents in this group believed that pronunciation should be a reciprocal effort between international students and individuals from the host society, such that both ought to make an effort to learn to say each other's names (Reciprocal Efforts; e.g., "No one should have to settle for a mispronunciation, especially when international students try so hard to pronounce other heritage or English names accurately"). In a similar vein, other respondents believed that their heritage names deserved to be pronounced correctly (Deserving of Correct Pronunciation; e.g., "Because... it deserves to be pronounced properly"), and appreciated others who took an effort in learning about their names (Appreciation for Pronunciation Efforts; e.g., "Because my name is mine. And as a part of who I am, I'd appreciate others taking the effort to learn how to say it properly").

Two responses did not explain why correct heritage name pronunciation is relatively important (Importance Unexplained; e.g., "I think pronounced my heritage name is very important to me"), and one response was categorized as "Linguistic prescriptivism" because it did not overlap with any other reasons (e.g., "I mean it is honestly the same reason as to why pronunciation rules for the english dictionary exists. There is a certain way it should be pronounced and that is pretty much it"). Three participants did not provide a response.

On top of the ranked reasons emphasizing accurate name pronunciation, a theme emerged in the responses that spoke to the respondents' understanding toward the mispronunciations of host members due to language barriers and difficulties. For instance, one respondent indicated, "It is important to have one's heritage name correctly pronounced but sometimes it can be understand. Because they are not on purpose. Same as me, I don't know how to pronounce some foreigners name either."

\section{Somewhat Important}

Participants who perceived correct heritage name pronunciation to be somewhat important ( $n=36$; see Table 4) provided rationales that included the characteristics of the previous two groups. In other words, their views on the importance of accurate heritage name pronunciation were relatively moderate and sometimes ambivalent.

Table 4: Themes in the Personal Reasons of International Students Perceiving Correct Heritage Name Pronunciations as Somewhat Important $(n=36)$

\begin{tabular}{lcl}
\hline Ranking & $\begin{array}{l}\text { Number of } \\
\text { references }\end{array}$ & Themes \\
\hline & & Reasons Supporting Importance \\
1 & 13 & Personal Associations \\
2 & 11 & Respect \\
3 & 5 & Facilitating Social Recognition \\
4 & 2 & Positive Personal and Social Outcomes \\
\hline
\end{tabular}




\begin{tabular}{lll}
\hline Ranking & $\begin{array}{l}\text { Number of } \\
\text { references }\end{array}$ & Themes \\
\hline 1 & 13 & $\begin{array}{l}\text { Reasons Supporting Lack of Importance } \\
\text { Acknowledging and Understanding } \\
\text { Pronunciation Difficulty } \\
2\end{array}$ \\
\hline & 3 & $\begin{array}{l}\text { English Name Use \& Preference } \\
\text { Other Reasons }\end{array}$ \\
\hline
\end{tabular}

Note: Number of references refers to the total number each corresponding theme has appeared in the responses. Themes are ranked from the most referenced to the least referenced.

Among responses that stressed the importance of pronunciation accuracy, Personal Associations appeared to be the most prominent reason. These students believed that their names held significant meanings at the individual level (e.g., personal identity, "My heritage name is my identity and it's much more than just a name..."), family level (e.g., family history and parental blessings, "The name itself... when paired with my family history and who I am, it speaks volumes," "My heritage name does mean something to me for sure as it comes from my parents' blessing..."), and the ethnocultural level (e.g., representative of one's home country, “... it conveys about my ethnic background and my identity in this diverse community as an individual"). Next, correct pronunciation was emphasized because it conveyed respect toward the students' families, cultures, as well as to themselves as individuals (Respect; e.g., "It is important because correctly pronouncing my heritage name is the way people respect me, my family, and my ethnicity," "Because it is also somewhat my culture, all should give respect"). Moreover, correct heritage name pronunciation was regarded as important because it helped international students to be better identified and recognized in the host social context (Facilitating Social Recognition; e.g., "Because if... someone cannot accurately pronounced my heritage name, I don't have awareness of calling me..."). In addition, accurate name pronunciations may help to build a positive social impression (Positive Personal and Social Outcomes; e.g., "Pronouncing my name correct... will give me a good impression and respect").

However, among responses that conveyed a lack of importance to correct heritage name pronunciations, the most prominent rationale concerned language barriers and differences, especially for non-native speakers (Acknowledging and Understanding Pronunciation Difficulty; e.g., "Since it an Arabic name it is hard for people to pronounce some of the phonemes in the language"). The second prominent reason was related to the use of and preference for English names in Canada (English Name Use \& Preference; e.g., "I never mind the name that they pronounced to my heritage name, I use my English name frequently").

Two responses were grouped into the "Others" category, as they did not overlap with the other identified reasons (e.g., "My heritage name is my english name"). Two participants did not provide a response. 


\section{DISCUSSION}

The findings indicate that heritage name mispronunciations were frequently experienced by the language-minority international students at this Canadian university. Despite the frequent occurrences, fewer than half of the sample believed that it was important for others to pronounce their heritage names accurately, which was contrary to our expectation that higher frequency in mispronunciation would be accompanied with greater concern. As well, there are few systematic differences in the frequency and importance of inaccurate name pronunciation across the participants' gender, nationality, year of study, and future residency plan in Canada.

To facilitate the discussion on the personal reasons underlying the perceived importance to accurate pronunciations, the reported themes were inferred into three categories of meta-themes that encompass "self-," "utility," and "other-" related reasons behind the importance perception. The first self-related reason was "identity," such that respondents who assigned greater importance to accurate pronunciation reported close ties between their heritage name and their individual and collective identity. Conversely, a lack of personal significance in one's name was one reason for indifference to pronunciation accuracy. Relatedly, "affect" was another self-related reason that seemed to impact the importance perceptions, so that respondents who regarded pronunciation accuracy as important expressed emotional ties to both their name (e.g., love, liking) and the accuracy of its pronunciation (e.g., a feeling of proper acknowledgment, respect). In sum, the more names were entwined with the self, the more emphasis respondents placed on pronunciation accuracy.

The perceived importance of pronunciation accuracy was also connected with the "utility" function of pronunciation accuracy. Specifically, whether mispronunciations were seen as impactful was associated with the perceived interference to social recognition for language-minority international students in the host country. Accordingly, respondents who experienced inconvenience in using their heritage names due to communication and recognition barriers tend to acknowledge the importance of accurate pronunciation, whereas those who reported no concerns with using their heritage names tend to overlook hosts' mispronunciations. Otherwise stated, whether pronunciation accuracy was deemed important or not might be partially dependent on the "utility," or the practical convenience in using a particular name in a given social interaction.

The last reason that differentiated the respondents' importance perceptions appeared to be "other-oriented," which involves "empathy for non-native speakers." Empathy is generally defined as the ability to join another in their current experiences, while maintaining a sense of self (Ivey et al., 1993). Empathic understanding of non-native speakers' pronunciation struggles might have oriented the respondents' expectations to a lower and perhaps more realistic level, thereby reducing the significance attached to mispronunciations. The connection between empathy and attitudes toward name mispronunciations was a novel finding from the thematic results, which had not been addressed by previous literature on name mispronunciations and warrants further research attention. 
Additionally, the findings suggest that the respondents construed heritage name mispronunciations both as communicative inconveniences (hassles) and as a sign of disrespect to their heritage culture, depending on individual perceptions. This dual interpretation may explain why respondents who perceived mispronunciations to be relatively minor still appreciated hosts' pronunciation accuracy and efforts. Thus, labeling mispronunciations as daily hassles cannot eliminate the potential existence of deeper issues concerning intergroup attitudes (e.g., prejudice, microaggressions). Hence, it would be erroneous to assume that mispronunciation is always inconsequential and does not require effort in learning the accurate pronunciation of another's heritage name.

\section{Limitations and Future Research}

The present study offers insight into the frequency and importance of heritage name mispronunciations. There are, however, some methodological limitations that suggest directions for future research. The first limitation pertains to the unequal distribution in the countries of origin among the respondents. With a majority of the sample arriving from East Asia, it raises generalizability concerns that call for a more representative sample to better capture the students' experiences and perspectives regarding hosts' mispronunciations of their heritage names.

The second limitation concerns the context in which attitudes toward hosts' mispronunciations were assessed. Specifically, because the current research was conducted in Canada, where ethnocultural diversity is widely embraced, it is possible that the mispronunciation of ethnic names is not strongly associated with prejudice or disrespect toward the students' ethnic roots as it might be in a setting where ethnolinguistic relations are more fraught. As well, since heritage differences are celebrated in Canada, Canadians living in such a multicultural context may be more mindful in learning the authentic pronunciation of another's name, thereby reducing the frequency of perceived mispronunciations. To address these limitations, replications of the present study across contexts that vary in ethnic diversity and attitudes toward foreign students would help to determine the broader contextual influences that impact language-minority students' attitudes toward hosts' mispronunciations.

Further, the present study identified a few reasons that emphasize the need for accurate heritage name pronunciation, to assist language-minority international students' adaptation to the new society (e.g., facilitating social interactions and strengthening relational closeness to local community). The next step in a research program would be to examine causal relations between those reasons and adjustment outcomes. Longitudinal studies could examine the predictive power of hosts' pronunciation accuracy on international students' psychosocial functioning in the host country (e.g., sense of connectedness, local social networks, positive affect), possibly via cross-lagged panel analysis. The establishment of causality between mispronunciations, adjustment challenges, and negative affect highlights the significance of pronunciation accuracy and contributes to building prevention efforts with the goal of constructing a 
comfortable and supportive environment for diverse language-minority international students.

Finally, to gain an in-depth understanding of how hosts' pronunciation accuracy impacts the lives of international students, perspectives from host nationals on heritage name mispronunciations ought to be assessed as well. In comparison with the students' responses, examination of hosts' input assists to establish a well-rounded understanding of how pronunciation accuracy may impact (1) the relational quality between hosts and international students, and (2) the students' emotional well-being (e.g., positive affect, a sense of social connectedness and belonging).

\section{Implications for Practice and Theory}

The present study has highlighted several benefits in hosts' pronunciation accuracy, in facilitation of international students' cross-cultural adjustment. First, heritage names may be closely aligned with the students' sense of self, and with their ethnic identities. Thus, rightful acknowledgment of international students' heritage names communicates respectful recognition of the students on an individual and cultural basis. Second, accurate pronunciations may instill a feeling of familiarity among international students in a foreign country via the production of familiar linguistic accents, which may help to reduce the cultural distance experienced by the students in the host country.

As well, consistent with the respondents' appreciation for hosts' pronunciation effort and accuracy, mindfulness in learning the authentic pronunciation of international students' names, although seemingly trivial, can signify the hosts' efforts in "walking toward" the students in attempt to reconcile the ethnolinguistic differences, and to demonstrate a sense of reciprocity in the immediate intercultural relationship. Particularly in nations that take pride in their inclusiveness, reciprocity in learning the correct pronunciation of another's name reflects a sincere attitude toward getting to know members of other ethnicities.

We strongly recommend the launch of name pronunciation workshops and services across institutions and communities to raise awareness on the potential impact of mispronunciations and to provide in-person training to individuals who wish to improve their pronunciation of language-minority names. Due to the disparities in sample size, we were unable to conclude whether certain ethnic groups were more impacted by mispronunciations. Hence, future research is recommended to assess diverse participants in similar numbers to more accurately examine whether the names of certain ethnolinguistic groups should be prioritized in these workshops due to higher needs.

Finally, the thematic findings suggest that heritage name mispronunciations could be construed either as "hassles" (e.g., communicative inconveniences) or as "microaggressions" (e.g., racial disrespect), despite their differences in definition and theoretical origins. Arguably, because the term stems from research in aggression (Smith et al., 2007), "microaggression" tends to connote greater intentionality and emotional harm than "hassles." However, the relatively benign term of "daily hassles" does not necessarily mean that they are always trivial in 
nature. The same encounter could be construed as either a hassle or a microaggression, depending on the intention of the speaker and the interpretation of the listener. In light of this, researchers ought to assess both the speaker's intention and the student's interpretation before they designate an incident of mispronunciation as a hassle or a microaggression. As with all psychological constructs, we need to look past the surface level of any social behavior, regardless of how "minor" it appears, in attempt to unveil the deeper issues that may perpetuate its occurrence (e.g., negative attitudes, systemic discrimination, etc.).

\section{CONCLUSION}

With a change in linguistic context, international students are prone to experiencing mispronunciation of their heritage names in the host country, as well as its deleterious effects. The current study provides an important step in orienting research attention to understanding the frequency and impact of heritage name mispronunciations from the perspectives of ethnolinguistic minority international students in Canada.

As a hassle commonly experienced by international students in foreign language contexts, mispronunciation of heritage names may often be overlooked due to its seemingly harmless impact on the interactants. However, the present study alleges that international students value pronunciation accuracy and efforts from host members, because heritage names can be closely associated with the students' individual and collective identity, and personal affect. As well, the findings underlined that hosts' pronunciation accuracy and efforts may have a facilitative effect on international students' sociocultural functioning, via (1) reducing the complications associated with using heritage names during intercultural interactions, and (2) instilling relational connectedness to the host community. Most importantly, attentiveness in learning the correct pronunciation of various ethnic names not only brings rightful acknowledgment to the namebearers, it is also indicative of hosts' active efforts in welcoming ethnic minority international students into the local community. In doing so, we can help to cocreate an inclusive and supportive environment that promotes the wellness and successful cross-cultural transitions of diverse international students.

\section{REFERENCES}

Alford, R. D. (1988). Naming and identity. A cross-cultural study of personal naming practices. HRAF.

Blatchford, A. (2019, May 17). Canada wants more international students - but getting a visa isn't easy for some. Global News. https:/globalnews.ca/ news/5267063/canada-international-students-visa/

Bramwell, E. (2016). Personal names and anthropology. In C. Hough (Ed.), The Oxford handbook of names and naming (pp. 52-66). Oxford University Press. https://doi.org/10.1093/oxfordhb/9780199656431.013.29 
Brandes, S. H. (1975). The structural and demographic implications of nicknames in Navanogal, Spain. American Ethnologist, 2, 139-148. https://doi.org/ 10.1525/ae.1975.2.1.02a00080

Braun, V., \& Clarke, V. (2006). Using thematic analysis in psychology. Qualitative Research in Psychology, 3, 77-101. https://doi.org/10.1191/ 1478088706qp063oa

Canadian Alliance of Student Associations. (2018). Value beyond the dollars and cents: International students' contributions to Canada and their need for supports [Policy paper]. https://d3n8a8pro7vhmx.cloudfront.net/casaacae/ pages/2693/attachments/original/1535747003/Value_Beyond_the_Dollars and_Cents_International_Students'_Contributions_to_Canada_and_Their Need_for_Supports.pdf? $153574700 \overline{3}$

Canadian Bureau for International Education. (2019). International students in Canada. https://cbie.ca/infographic/

Chelliah, S. L. (2005). Asserting nationhood through personal name choice: The case of the Meithei of Northeast India. Anthropological Linguistics, 47, $169-216$.

Chen, Y.-A. J. (2016). English name transition from Taiwan to the United States: A case study of Taiwanese international students. International Journal of Applied Linguistics and English Literature, 5, 58-64. https://doi.org/ 10.7575/aiac.ijalel.v.5n.4p.58

Cohen J. (1988). Statistical power analysis for the behavioral sciences. Routledge Academic.

Cornford, F. M. (1957). Platos theory of knowledge. Bobbs-Merrill.

Edwards, R., \& Caballero, C. (2008). What's in a name? An exploration of the significance of personal naming of 'mixed' children for parents from different racial, ethnic and faith backgrounds. The Sociological Review, 56(1), 39-60. https://doi.org/10.1111/j.1467-954x.2008.00776.x

Ivey, A. E., Ivey, M. B., \& Simek-Morgan, L. (1993). The empathic attitude: Individual, family, and culture. In A. Ivey \& L. Simek-Morgan (Eds.), Counseling and psychotherapy: A multicultural perspective (3rd ed., pp. 2144). Allyn \& Bacon.

Kim, A. S. (2019, August 8). Shuai Vs. Sean: What's in an English name for students? CONTACT Magazine. http://contact.teslontario.org/shuai-vs-seanwhats-in-an-english-name-for-students/

Kim, H. Y. (2011). International graduate students' difficulties: Graduate classes as a community of practices. Teaching in Higher Education, 16(3), 281-292. https://doi.org/10.1080/13562517.2010.524922

Kohli, R., \& Solórzano, D. G. (2012). Teachers please learn our names! Racial microaggressions and the K-12 classroom. Race Ethnicity and Education, 15, 441-462. https://doi.org/10.1080/13613324.2012.674026

Le, C. N. (2018). Building cultural bridges and supporting prospective Chinese international students at U.S. universities. In Y. Ma \& M. Garcia-Murillo (Eds.), Understanding international students from Asia in American universities (pp. 63-80). Springer. 
Leibring, K. (2016). Given names in European naming systems. In C. Hough (Ed.), The Oxford handbook of names and naming (pp. 199-213). Oxford University Press. https://doi.org/10.1093/oxfordhb/9780199656431.013.51

Leong, C. H., \& Ward, C. (2000). Identity conflict in sojourners. International Journal of Intercultural Relations, 25(6), 763-776. https://doi.org/ 10.1016/s0147-1767(00)00030-4

Lincoln, Y. S., \& Guba, E. G. (1986). 'But is it rigorous? Trustworthiness and authenticity in naturalistic evaluation'. In D. D. Williams (Ed.), Naturalistic evaluation (pp. 73-84). Jossey-Bass.

Martirosyan, N., Bustamante, R., \& Saxon, D. (2019). Academic and social support services for international students. Journal of International Students, 9(1), 172-191. https://doi.org/10.32674/jis.v9i1.275

Morse, J. M., \& Cheek, J. (2014). Making room for qualitatively-driven mixedmethod research. Qualitative Health Research, 24, 3-5. https://doi.org/ $10.1177 / 1049732313513656$

Nyström, S. (1998). Names in the mind. Aspects of the mental onomasticon. In W. F. H. Nicolaisen (Ed.), Proceedings of the XIXth international congress of onomastic sciences, Aberdeen, August 4-11, 1996. Scope, perspectives and methods of onomastics, vol. 1 (pp. 229-235). Department of English, University of Aberdeen.

Nyström, S. (2016). Names and meaning. In C. Hough (Ed.), The Oxford handbook of names and naming (pp. 39-51). Oxford University Press. https://doi.org/10.1093/oxfordhb/9780199656431.013.26

Payne, K. E., Philyaw, Z., Rabow, J., \& Yazdanfar, S. (2018). Names: A new dimension of transformation. Race Ethnicity and Education, 21(4), 564-571. https://doi.org/10.1080/13613324.2016.1248832

Pennesi, K. E. (2014). Reading and righting the names at a convocation ceremony: Influences of linguistic ideologies on name usage in an institutional interaction. Names, 62(1), 37-48. https://doi.org/10.1179/0027773813z. 00000000070

Pennesi, K. E. (2016). They can learn to say my name: Redistributing responsibility for integrating immigrants to Canada. Anthropology Publications, 58(1), 46-59. https://doi.org/10.3138/anth.581.a03

Quaglia, R., Longobardi, C., Mendola, M., \& Prino, L. E. (2016). Names in psychological science: Investigating the processes of thought development and the construction of personal identities. Integrative Psychological \& Behavioral Science, 50, 277-295. https://doi.org/10.1007/s12124-015-9326-2

Ruzicka, G. R. (2018). What's in a name? Exploring Anglicized naming practices amongst Chinese international students (Publication No. 3278) [Master's thesis, Missouri State University]. BearWorks. https://bearworks. missouristate.edu/theses $/ 3278$

Sidhu, D. M., \& Pexman, P. M. (2019). The sound symbolism of names. Current Directions in Psychological Science, 28, 398-402. https://doi.org/10.1177/ 0963721419850134 
Smith, W. A., Allen, W. R., \& Danley, L. L. (2007). “Assume the position. . you fit the description": Psychosocial experiences and racial battle fatigue among African-American male college students. American Behavioral Scientist, 51, 551-578. https://doi.org/10/1177/0002764207307742

University of Alberta. (2020). Annual report on undergraduate enrolment 2019/20. https://www.registrar.ualberta.ca/emreport/Undergraduate_Enrolment Annual_Report_2019-2020.pdf

Yoon, J. (2018). At 11, I left Korea with one name. I arrived in Canada with another. $C B C$. https://www.cbc.ca/radio/docproject/a-tale-of-two-jennifers1.4916158/at-11-i-left-korea-with-one-name-i-arrived-in-canada-with-another1.4916162

Zhao, X., \& Biernat, M. (2018). "I have two names, Xian and Alex": Psychological correlates of adopting Anglo names by Chinese students. Journal of Cross-Cultural Psychology, 49, 587-601. https://doi.org/10.1177/ 0022022118763111

Zittoun, T. (2004). Symbolic competencies for developmental transitions: The case of the choice of first names. Culture \& Psychology, 10(2), 131-161. https://doi.org/10.1177/1354067X04040926

YING SHAN DORIS ZHANG, MA, is a PhD candidate in the Department of Psychology at the University of Alberta. Her major research interests lie in the area of acculturation, intercultural communication, and relations, as well as the cross-cultural adjustment of international students and immigrants. Email: ydz@ualberta.ca

KIMBERLY A. NOELS, PhD, is a professor in the Department of Psychology at the University of Alberta. Her major research interests lie in the area of language, intercultural communication, interethnic relations, and acculturation. Email:knoels@ualberta.ca 